\title{
Effects of High-Dose Vitamin D Supplementation on Metabolic Status and Pregnancy Outcomes in Pregnant Women at Risk for Pre-Eclampsia
}

Authors

Affiliations

\author{
M. Karamali ${ }^{1}$, E. Beihaghi ${ }^{1}$, A. A. Mohammadi² ${ }^{2}$ Z. Asemi ${ }^{3}$
}

Department of Gynecology and Obstetrics, School of Medicine, Arak University of Medical Sciences, Arak, I. R. Iran Department of Nutrition, School of Public Health, Iran University of Medical Sciences, Tehran, I. R. Iran Research Center for Biochemistry and Nutrition in Metabolic Diseases, Kashan University of Medical Sciences, Kashan, I. R. Iran
Key words

vitamin D supplementation

metabolic profiles

pregnancy outcomes

pre-eclampsia received $\quad 02.02 .2015$

accepted 11.03.2015

\section{Abstract}

$\nabla$

This study was designed to assess the beneficial effects of high-dose (cholecalciferol) vitamin $D$ supplementation on metabolic profiles and pregnancy outcomes among pregnant women at risk for pre-eclampsia. This randomized double-blind placebo-controlled clinical trial was performed among 60 pregnant women at risk for pre-eclampsia according to abnormal uterine artery Doppler waveform. Subjects were randomly divided into 2 groups to receive 50000 IU vitamin D supplements $(n=30)$ or receive placebo $(n=30)$ every 2 weeks from 20 to 32 weeks of gestation. Fasting blood samples were taken at baseline study and 12 weeks after the intervention to quantify relevant variables. Newborn's anthropometric measurements were determined. Pregnant women who received cholecalciferol supplements had significantly increased serum 25-hydroxyvitamin D concentrations $(+17.92 \pm 2.28$ vs. $+0.27 \pm 3.19 \mathrm{ng} /$ $\mathrm{ml}, \mathrm{p}<0.001$ ) compared with the placebo. The administration of cholecalciferol supplements, compared with the placebo, resulted in signifi- cant differences in serum insulin concentrations $(+1.08 \pm 6.80$ vs. $+9.57 \pm 10.32 \mu \mathrm{IU} / \mathrm{ml}, \mathrm{p}<0.001)$, homeostasis model of assessment-insulin resistance (HOMA-IR) $(+0.19 \pm 1.47$ vs. $+2.10 \pm 2.67$, $\mathrm{p}<0.001)$, homeostatic model assessment-beta cell function (HOMA-B) $(+5.82 \pm 29.58$ vs. +39.81 $\pm 38.00, p<0.001)$ and quantitative insulin sensitivity check index (QUICKI) score $(-0.009 \pm 0.03$ vs. $-0.04 \pm 0.03, p=0.004)$. Furthermore, cholecalciferol-supplemented pregnant women had increased HDL-cholesterol concentrations $(+2.67$ \pm 8.83 vs. $-3.23 \pm 7.76 \mathrm{mg} / \mathrm{dl}, \mathrm{p}=0.008$ ) compared with the placebo. Finally, cholecalciferol supplementation led to a significant rise in plasma total antioxidant capacity (TAC) concentrations $(+79.00 \pm 136.69$ vs. $\quad-66.91 \pm 176.02 \mathrm{mmol} / \mathrm{l}$, $\mathrm{p}=0.001$ ) compared with the placebo. Totally, the administration of cholecalciferol supplements among pregnant women at risk for pre-eclampsia for 12 weeks had favorable effects on insulin metabolism parameters, serum HDL-cholesterol, and plasma TAC concentrations.

Supporting Information for this article is available online at http://www.thieme-connect.de/products.

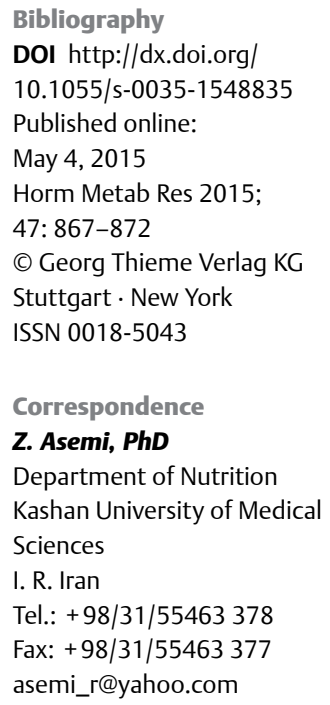

$\begin{array}{ll}\text { Abbreviations } \\ \text { CHD } & \text { Coronary heart disease } \\ \text { DBP } & \text { Diastolic blood pressure } \\ \text { FPG } & \text { Fasting plasma glucose } \\ \text { FRAP } & \text { Ferric reducing antioxidant power } \\ \text { GSH } & \text { Glutathione } \\ \text { GDM } & \text { Gestational diabetes } \\ \text { GPX } & \text { Glutathione peroxidase } \\ \text { HOMA-IR } & \text { Homeostasis model of assessment- } \\ & \text { estimated insulin resistance } \\ \text { HOMA-B } & \text { Homeostasis model of assessment- } \\ & \text { estimated B cell function } \\ \text { hs-CRP } & \text { High-sensitivity C-reactive protein } \\ \text { IOM } & \text { Institute of Medicine } \\ \text { LBW } & \text { Low birth weight } \\ \text { IL- } & \text { Interleukin-6 }\end{array}$

MDA Malondialdehyde

MUFA Monounsaturated fatty acid

NO Nitric oxide

NAFLD Nonalcoholic fatty liver disease

OSI Oxidative stress index

PTH Parathyroid hormone

PUFA Polyunsaturated fatty acid

QUICKI Quantitative insulin sensitivity check index

ROS Reactive oxygen species

SFA Saturated fatty acid

SOD Superoxide dismutase

SBP Systolic blood pressure

TAC Total antioxidant capacity

TBARs Thiobarbituric acid reactive substance

T2DM Type 2 diabetes mellitus

TNF- $\alpha$ Tumor necrosis factor alpha

TDF Total dietary fiber 


\section{Introduction}

$\nabla$

Pre-eclampsia is a disorder characterized by pregnancy-induced hypertension and new-onset proteinuria occurring after 20 weeks of gestation in a previously normotensive women [1]. The prevalence of pre-eclampsia has reported between $1.3-6.7 \%$ of all pregnancies [2]. Despite numerous attempts at early diagnosis and treatment, to date, no method has been found that prevents the development of pre-eclampsia [3]. Increased biomarkers of oxidative stress are considered to be a key factor in pre-eclampsia process [4]. In addition, decreased maternal plasma ascorbic acid concentrations [4], increased synthesis of free radicals and reactive oxygen species (ROS) in the placenta [5], and reduced activities of antioxidant enzymes [6] may lead to the development of pre-eclampsia.

Various therapeutic strategies for prevention of pre-eclampsia are proposed including the use of aspirin [7], antioxidant supplementation, especially vitamins C and E [8], and the use of low molecular weight heparin [9]. Previous studies have reported that intake of cholecalciferol supplements can rise glutathione levels and reduce the production of lipid peroxidation products $[10,11]$, which in turn, would result in decreased oxidative stress. These observations result in the hypothesis that early supplementation with high-dose cholecalciferol could be useful in decreased biomarkers of oxidative stress as well as improving vascular endothelial function, thereby preventing or ameliorating the course of pre-eclampsia. Taking 100000 IU vitamin D supplements among patients with gestational diabetes (GDM) showed improved insulin function, decreased total- and LDLcholesterol concentrations after 6 weeks [12]. In addition, in a meta-analysis study it has been shown that pregnant women who received vitamin $\mathrm{D}$ supplements in early pregnancy had lower odds of pre-eclampsia [13]. Vitamin D supplementation in healthy nulliparous women did affect pregnancy outcome with regard to pre-eclampsia [14].

The favorable effects of cholecalciferol supplementation on metabolic profiles and pregnancy outcomes might result from its effect on apolipoprotein gene expression [15], parathyroid hormone (PTH) suppression [16], improved insulin sensitivity [17], and decreased production of lipid peroxidation products [11]. We are aware that no study had examined the beneficial effects of high-dose cholecalciferol supplementation on metabolic profiles, biomarkers of inflammation, oxidative stress, and pregnancy outcomes in pregnant women at risk for pre-eclampsia. The current study was, therefore, performed to investigate the favorable effects of cholecalciferol administration on metabolic status and pregnancy outcomes in pregnant women at risk for pre-eclampsia.

\section{Subjects and Methods}

$\nabla$

\section{Participants}

Between July 2014 and October 2014, we did a randomized double-blind placebo-controlled clinical trial in Arak, Iran. For estimating sample size, we used a randomized clinical study sample size formula where type $1(\alpha)$ and type 2 errors $(\beta)$ were 0.05 and 0.20 (power $=80 \%$ ), respectively. According to a previous study [18], we also considered 0.9 as SD and $0.55 \mathrm{~cm}$ as the difference in the mean (d) of newborns' length at birth as the key variable. Based on this, we needed 25 pregnant women in each group to have $80 \%$ power of the study. However, we recruited 30 subjects in each group (totally, 60 patients) to compensate for the probable loss to follow-up. In the present study, our inclusion criteria were pregnant women primigravida, aged 18-40 years old and at risk for pre-eclampsia. Women were identified as "at-risk" by abnormal uterine artery Doppler waveform (1820 weeks' gestation, mean resistance index $>0.67$ or pulsatility index $>1.65$ with or without the presence of unilateral or bilateral diastolic notches) [19]. We excluded pregnant women who were unable or unwilling to give written informed consent, having abnormal fetal anomaly scan, or were being treated with warfarin. Gestational age was assessed from the date of last menstrual period and concurrent clinical assessment [20]. The present trial protocol was approved by the Ethics Committee of Arak University of Medical Sciences (AUMS) (Registration no. 92-12-161). All pregnant women signed the written informed consent to take part in the current study. This study was registered in the Iranian website (www.irct.ir) for registration of clinical trials (IRCT code: IRCT201410035623N27).

\section{Study design}

After stratification for pre-intervention BMI ( $<25$ and $\geq 25 \mathrm{~kg} /$ $\mathrm{m}^{2}$ ) and maternal age ( $<30$ and $\geq 30$ years), pregnant women were randomly allocated into 2 groups to take either cholecalciferol supplements $(n=30)$ or placebo $(n=30)$. A trained midwife at maternity clinic did the randomized allocation sequence with a computer random number generator. An investigator with no clinical involvement in our study packed cholecalciferol and placebos in numbered bottles based on the random list. Randomization and allocation were hidden from the researchers and pregnant women until the statistical analysis was completed. Pregnant women either received one oral pearl containing of 50000 IU vitamin D3 (D-Vitin 50000; Zahravi Pharm Co, Tabriz, Iran) or a placebo (Barij Essence Co, Kashan, Iran) every 14 days for 12 weeks from 20 to 32 weeks of gestation. Placebo pearls were similar in color, shape, size, and package to the vitamin D3 ones and contained edible paraffin. Subjects were requested not to alter their regular physical activity or normal dietary intakes throughout the study and not to take any supplements other than the one provided to them by the investigators. All pregnant women were also taking $400 \mu \mathrm{g} / \mathrm{d}$ folic acid from the start of pregnancy, $60 \mathrm{mg} / \mathrm{d}$ ferrous sulfate from the second trimester, and a multivitamin mineral capsule (containing 400 IU vitamin D) from the second half of pregnancy. Both dietary and physical activity records were taken at week 3, 6, and 9 of intervention. The dietary records were based on estimated values in household measurements. To obtain nutrient intakes of participants according to these 3-day food diaries, we used Nutritionist IV software (First Databank, San Bruno, CA, USA) modified for Iranian foods.

\section{Assessment of anthropometric variables}

Information on pre-pregnancy weight and BMI were obtained from the records of pregnant women existed in the clinic. A trained midwife at maternity clinic did anthropometric measurements at the beginning of the study and the end of the intervention. Height was measured without shoes using stadiometer with a precision of $0.1 \mathrm{~cm}$. Weight was measured in light clothing to the nearest $0.1 \mathrm{~kg}$. BMI was determined as weight $(\mathrm{kg})$ divided by squared height $\left(\mathrm{m}^{2}\right)$.

\section{Primary and secondary outcomes}

Primary outcomes were pre-eclampsia rate, low birth weight (LBW) $(<2500 \mathrm{~g})$, newborn's birth size, and preterm delivery 
(<37 weeks). Secondary outcomes were metabolic concentrations, biomarkers of inflammatory factors, oxidative stress, and blood pressures.

\section{Biochemical analysis}

Fasting blood samples $(10 \mathrm{ml})$ were taken at baseline and 12 weeks after the intervention at Arak reference laboratory at early morning after an overnight fast. Blood samples were immediately centrifuged (Hettich 78532, Tuttlingen, Germany) at $3500 \mathrm{rpm}$ for $10 \mathrm{~min}$ to separate serum. Then, the samples were stored at $-70^{\circ} \mathrm{C}$ before analysis at the AUMS reference laboratory. Serum 25-hydroxyvitamin D concentrations was assayed by a commercial ELISA kit (IDS, Boldon, UK). The interand intra-assay CVs for serum 25-hydroxyvitamin D assays ranged from 4.9 to $7.2 \%$. Commercial kits were used to measure fasting plasma glucose (FPG), triglycerides, cholesterol, VLDL-, LDL- and HDL-cholesterol concentrations (Pars Azmun, Tehran, Iran). The intra- and inter-assay CVs for FPG and lipid concentrations were $<5 \%$. Serum insulin was assayed by ELISA kit (Monobind, CA, USA). The intra- and inter-assay CVs for serum insulin were 2.9 and $5.9 \%$, respectively. Homeostasis model of assessment-insulin resistance (HOMA-IR) and $\beta$-cell function (HOMA-B) and quantitative insulin sensitivity check index (QUICKI) was calculated based on suggested formulas [21]. Serum high sensitivity C-reactive protein (hs-CRP) was quantified using ELISA kit (LDN, Nordhorn, Germany) with intra- and inter-assay CVs of 2.4 and $3.9 \%$, respectively. Plasma nitrite/ nitrate (NOx), taken as an index of nitric oxide (NO) concentration, was determined using the Giess method modified by Tatsh et al. [28]. Plasma total antioxidant capacity (TAC) was assessed by the use of ferric reducing antioxidant power (FRAP) method developed by Benzie and Strain [22]. The plasma total glutathione (GSH) and malondialdehyde (MDA) were measured by the method of Beutler et al. [23] and thiobarbituric acid reactive substance (TBARs) spectrophotometric test [24].

\section{Statistical analysis}

Distribution of data related to normality was assessed by Kolmogorov-Smirnov test. Independent sample Student's $t$-test was used to detect changes in general characteristics and dietary intakes between the 2 groups. Comparisons of changes (endpoint minus baseline) 12 weeks after the intervention between the 2 groups were done by two-way repeated measures analysis of variance. In this analysis, the treatment (cholecalciferol vs. placebo) was regarded as between-subject factor and time with 2 time-points (baseline and 12 weeks after the intervention) was considered as within-subject factor. To control for confounding variables, analysis of covariance (ANCOVA) test was used to determine the differences between the 2 groups postintervention, while adjusting for baseline measurements, maternal age and baseline BMI. A p-value of $<0.05$ was considered as statistically significant. All statistical analyses were done using the Statistical Package for Social Science version 17 (SPSS Inc., Chicago, IL, USA).

\section{Results}

Totally, 60 pregnant [cholecalciferol $(n=30)$ and placebo $(n=30)$ ] completed the trial. On average, the rate of compliance in our study was high, such that $100 \%$ of pearls were taken throughout the trial in both groups. Compliance with the consumption of vitamin D supplements and placebos was monitored every 2 weeks through telephone interviews and by the use of 3-day dietary records completed at week 3, 6, and 9 of intervention. Mean age, pre-pregnancy weight and BMI of pregnant women was $27.4 \pm 5.2$ years, $64.5 \pm 10.6 \mathrm{~kg}$ and $25.9 \pm 4.6 \mathrm{~kg} / \mathrm{m}^{2}$, respectively. Baseline and end-of-trial means of weight and BMI were not significantly different between cholecalciferol and placebo groups (Data not shown).

Based on the three-day dietary records obtained throughout the intervention, no significant change was seen between the two groups in terms of dietary intakes of energy, carbohydrates, proteins, fats, saturated fatty acids (SFA), polyunsaturated fatty acids (PUFA), monounsaturated fatty acids (MUFA), cholesterol, dietary fiber, vitamin $\mathrm{D}$, calcium, phosphors, magnesium, zinc, manganese, selenium, and vitamin C (Data not shown).

Pregnant women who received cholecalciferol supplements had significantly increased serum 25 -hydroxyvitamin D concentrations $(+17.92 \pm 2.28$ vs. $+0.27 \pm 3.19 \mathrm{ng} / \mathrm{ml}, \mathrm{p}<0.001)$ compared with the placebo ( $\bullet$ Table 1 ). The administration of cholecalciferol supplements, compared with the placebo, resulted in significant differences in serum insulin concentrations $(+1.08 \pm 6.80$ vs. $+9.57 \pm 10.32 \mu \mathrm{IU} / \mathrm{ml}, \quad \mathrm{p}<0.001), \quad$ HOMA-IR $(+0.19 \pm 1.47$ vs. $+2.10 \pm 2.67, \mathrm{p}<0.001)$, HOMA-B $(+5.82 \pm 29.58$ vs. $+39.81 \pm 38.00, \mathrm{p}<0.001)$ and QUICKI score $(-0.009 \pm 0.03$ vs. $-0.04 \pm 0.03, p=0.004)$. Furthermore, cholecalciferol-supplemented pregnant women had increased HDL-cholesterol concentrations $(+2.67 \pm 8.83$ vs. $-3.23 \pm 7.76 \mathrm{mg} / \mathrm{dl}, \mathrm{p}=0.008)$ compared with the placebo. Finally, cholecalciferol supplementation led to a significant rise in plasma TAC concentrations $(+79.00 \pm 136.69$ vs. $-66.91 \pm 176.02 \mathrm{mmol} / \mathrm{l}, \mathrm{p}=0.001)$ compared with the placebo. There were no significant differences between the cholecalciferol and placebo groups in terms of changes in FPG, other lipid profiles, biomarkers of inflammation and oxidative stress and blood pressures.

Baseline levels of SBP were significantly different between the 2 groups. Therefore, we controlled the analyses for the baseline levels. However, after this adjustment no significant changes in our findings occurred, except for plasma NO levels $(\mathrm{p}<0.001)$ Table S1. Further adjustments for maternal age and baseline BMI did not affect our findings, except for serum HDL-cholesterol levels $(p=0.06)$ and systolic blood pressure (SBP) $(p=0.04)$.

We did find no significant change in cesarean section rate, gestational age, preterm delivery, newborn's birth size, Apgar scores, pre-eclampsia rate and LBW comparing the 2 groups ( $\bullet$ Table 2 ).

\section{Discussion \\ $\nabla$}

The current study demonstrated that high-dose vitamin D administration among women at risk for pre-eclampsia had beneficial effects on insulin metabolism parameters, serum HDL-cholesterol, and plasma TAC concentrations, but did not affect FPG, other lipid profiles, inflammatory factors and other biomarkers of oxidative stress. To the best of our knowledge, the current study is the first evaluating the effects of high-dose cholecalciferol administration on metabolic status and pregnancy outcomes in pregnant women at risk for pre-eclampsia according to abnormal uterine artery Doppler waveform. It must be kept in mind that participants in the current study were pregnant women who have vitamin $\mathrm{D}$ deficiency by definition and in addition they have a very low vitamin $\mathrm{D}$ intake. Therefore, vitamin D supplementation with appropriate dosage is suggested in 


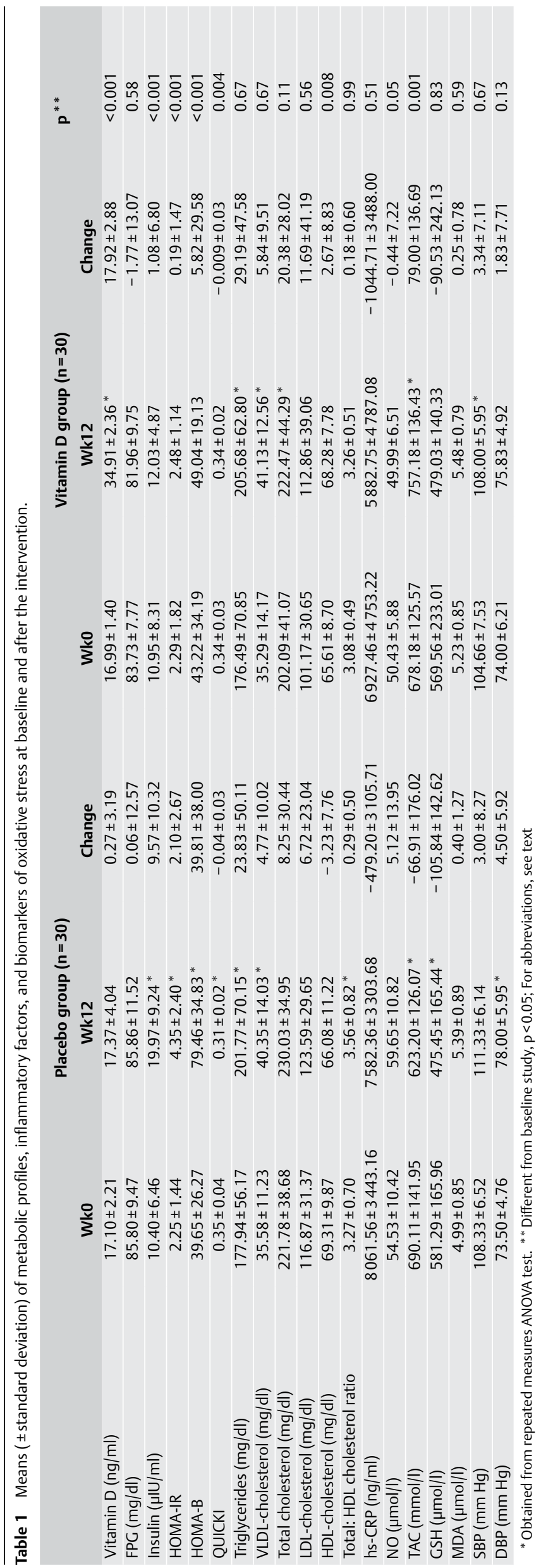

Table 2 The effect of vitamin D supplementation on pregnancy outcomes. *

\begin{tabular}{|c|c|c|c|}
\hline & $\begin{array}{l}\text { Placebo group } \\
(n=30)\end{array}$ & $\begin{array}{l}\text { Vitamin D } \\
\text { group }(n=30)\end{array}$ & $\mathbf{p}^{* *}$ \\
\hline Cesarean section (\%) & $10(33.3)$ & $9(30.0)$ & $0.78^{\dagger}$ \\
\hline Gestational age (weeks) & $39.1 \pm 1.3$ & $39.4 \pm 1.3$ & 0.31 \\
\hline Preterm delivery (\%) & $1(3.3)$ & $0(0)$ & $0.31^{\dagger}$ \\
\hline Newborns' weight (g) & $3141.0 \pm 495.9$ & $3313.6 \pm 341.1$ & 0.12 \\
\hline Newborns' length $(\mathrm{cm})$ & $50.4 \pm 2.1$ & $50.9 \pm 1.5$ & 0.29 \\
\hline Newborns' head circumference $(\mathrm{cm})$ & $34.7 \pm 1.5$ & $34.4 \pm 0.8$ & 0.26 \\
\hline 1-min Apgar score & $8.9 \pm 0.2$ & $8.9 \pm 0.3$ & 0.30 \\
\hline 5-min Apgar score & $9.9 \pm 0.2$ & $9.9 \pm 0.3$ & 0.30 \\
\hline Pre-eclampsia rate (\%) & $3(10.0)$ & $1(3.3)$ & $0.30^{\dagger}$ \\
\hline LBW (\%) & $2(6.7)$ & $0(0)$ & $0.15^{\dagger}$ \\
\hline \multicolumn{4}{|l|}{${ }^{*}$ Values are means \pm SDs } \\
\hline${ }^{* *}$ Obtained from independent $t$-test & & & \\
\hline quare & & & \\
\hline
\end{tabular}

vitamin $\mathrm{D}$ deficient pregnant women. In addition, we used a dose of approximately $4000 \mathrm{IU}$ vitamin $\mathrm{D}$ supplements daily in the current study, which is higher than the current recommended dietary allowance (600IU/day) or standard prenatal supplement dose ( $400 \mathrm{IU} /$ day). However, this dose is the tolerable upper intake levels advised by the Institute of Medicine (IOM) [25] and this is no problem in this short study of 12 weeks. Pre-eclampsia is associated with fetal and maternal complications [26]. Our study demonstrated that high-dose cholecalciferol intake for 12 weeks in women at risk for pre-eclampsia resulted in significant differences in serum insulin concentrations, HOMA-IR score, HOMA-B, and QUICKI score compared with the placebo, but did not affect FPG. Moreover, only limited data are available assessing the beneficial effects of cholecalciferol administration on metabolic status in pregnant women at risk for pre-eclampsia. Among women without risk for preeclampsia as well as in animal models, the favorable effects of taking vitamin $\mathrm{D}$ on glucose homeostasis parameters have been shown. In agreement with our study, Soheilykhah et al. [27] showed that $50000 \mathrm{IU}$ cholecalciferol intake every 2 weeks from week 12 of pregnancy until delivery led to improved insulin resistance in healthy pregnant women. In our previous study among women with GDM, we also observed improved markers of insulin metabolism following the consumption of $100000 \mathrm{IU}$ cholecalciferol supplements for 6 weeks [12]. However, some researchers did not see such beneficial effects of cholecalciferol administration on insulin function. For instance, taking vitamin D supplements had no beneficial effects on insulin resistance in patients with type 2 diabetes mellitus (T2DM) after 24 weeks of intervention [28] and after 6 months of therapy [29]. Furthermore, supplementation with $1000 \mathrm{IU}$ vitamin $\mathrm{D}$ daily did not affect insulin resistance among healthy overweight or obese women for 12 weeks [30]. Impaired insulin metabolism is associated with arterial stiffness and coronary heart disease (CHD) independent of glucose tolerance status and increased hypertension [31]. Increased cholecalciferol concentration suppression of inflammatory factors and increased expression of the insulin receptor and/or proteins of the insulin-signaling cascade may result in improved insulin function [32].

Findings from the current study showed that pregnant women who received high-dose of vitamin $D$ supplements had a significant rise in serum HDL-cholesterol concentrations compared with the placebo, but had no significant improvement in other 
lipid profiles. In line with our study, a 2-month supplementation of 100000 IU vitamin D increased HDL-cholesterol concentrations in school children [33]. In addition, vitamin D plus calcium administration (400 IU of vitamin D3 daily $+1000 \mathrm{mg}$ of elemental calcium) resulted in a significant increase in HDL-cholesterol concentrations among postmenopausal women [34]. However, some researchers did not observe any significant effect of taking cholecalciferol supplements on lipid concentrations $[35,36]$. Increased HDL-cholesterol concentrations in the presents study may result from form the stimulation of apolipoprotein A1 by cholecalciferol [37]. The absence of significant effect of taking cholecalciferol supplements on other lipid profiles in our study might be explained by distinct trial designs, various dosages of cholecalciferol supplementation, and subjects of the study.

We have revealed here that the administration of cholecalciferol supplements did not affect serum hs-CRP and plasma NO levels in pregnant women at risk for pre-eclampsia. In accordance with the present study, no significant change in CRP concentrations was observed after the vitamin D intake $(1000,2000$, or $4000 \mathrm{IU} /$ day of vitamin D3 orally) for 3 months [38]. Furthermore, $1000 \mathrm{mg}$ calcium per day and $50000 \mathrm{IU}$ vitamin D3 pearl 2 times during the study (at study baseline and day 21 of intervention) co-supplementation did not affect hs-CRP and NO concentrations among GDM patients after 6 weeks [10]. In disagreement, a 9-week administration of $400 \mathrm{IU}$ vitamin D supplements was associated with a significant decrease in serum hs-CRP concentrations among healthy pregnant women [39]. In addition, in an in vitro study, concomitant incubation with $1,25(\mathrm{OH})_{2} \mathrm{D}$ reduced interleukin-6 (IL-6) by $32 \%$, and of IL- 8 levels by $34 \%$ [40].

We have demonstrated that high-dose cholecalciferol intake resulted in a significant rise in plasma TAC concentrations in pregnant women at risk for pre-eclampsia compared with the placebo, but did not influence on other biomarkers of oxidative stress. In consistent with this trial, cholecalciferol supplementation significantly decreased liver oxidative stress index (OSI) and improved serum TAC concentrations in diabetic rats [41]. In addition, our findings are in accordance with those reported by other researchers, showing decreased oxidative DNA damage in the normal human colorectal mucosa following cholecalciferol and calcium supplementation [42]. However, supplementation of $50000 \mathrm{IU}$ vitamin D3 every 14 days for 4 months among adult patients with nonalcoholic fatty liver disease (NAFLD) did not affect TAC concentrations, but led to amelioration in MDA concentrations [11]. Increased oxidative stress and free radicals is regarded as a main factor in the pathogenesis and progression of diabetes mellitus and cardiovascular complications [43]. Accurate explanation to the antioxidative effects of cholecalciferol supplements cannot be provided, but these may include stabilization of the plasma membrane against lipid peroxidation [44] or upregulation of antioxidant systems including glutathione peroxidase (GPX) and superoxide dismutase (SOD), via its nuclear receptors [45].

The current study revealed no significant effect of high-dose cholecalciferol supplementation on pregnancy outcome. Our findings are accordance with previous studies showing supplementation with cholecalciferol did show no association between maternal vitamin D status in HIV-infected pregnant women and adverse pregnancy outcomes [46]. In addition, taking $25 \mathrm{mg} / \mathrm{d}$ ergocalciferol in pregnant women did not influence mean birth weight in other studies $[47,48]$. Others did not find a significant effect of vitamin D effect on pregnancy outcomes $[49,50]$. Discrepancies between our study and others might be explained by the different doses of cholecalciferol used as well as participants of the study.

While interpreting some limitations need to be taken into account. Due to limited funding, we in the current study did not assess the effect of cholecalciferol administration on other biomarkers of systemic inflammation including interleukin 1(IL-1), IL-6, and tumor necrosis factor alpha (TNF- $\alpha$ ) as well as biomarkers of oxidative stress such as catalase and SOD. Furthermore, the appropriate dosage of vitamin D supplementation in pregnant women with at risk for pre-eclampsia cannot be inferred from this study and additional data would be required. In conclusion, the administration of cholecalciferol supplementation for 12 weeks had favorable effects on insulin metabolism parameters, serum HDL-cholesterol and plasma TAC concentrations, while it did not affect FPG, other lipid concentrations, inflammation, oxidative stress, blood pressures, and pregnancy outcomes.

\section{Author Contributions}

$\nabla$

ZA contributed in conception, design, statistical analysis, and drafting of the manuscript. MK and EB contributed in conception, data collection, and manuscript drafting. All authors read and approved the final version of the paper. ZA is the guarantor of this work.

\section{Acknowledgements \\ $\nabla$}

This trial was supported by a grant from the Vice-chancellor for Research, AUMS, and Iran. The authors would like to thank the staff of Taleghani and Emam Reza Clinics (Arak, Iran) for their help in this study. The study was supported by a grant (no. 92-12-161) from Arak University of Medical Sciences.

\section{Conflict of Interest}

$\nabla$

The authors declare no conflict of interest.

\section{References}

1 Holmes VA, McCance DR. Could antioxidant supplementation prevent pre-eclampsia? Proc Nutr Soc 2005; 64: 491-501

2 Conde-Agudelo A, Romero R, Kusanovic JP, Hassan SS. Supplementation with vitamins $C$ and $E$ during pregnancy for the prevention of preeclampsia and other adverse maternal and perinatal outcomes: a systematic review and metaanalysis. Am J Obstet Gynecol 2011; 204: 503 e1-503 e12

3 Beazley D, Ahokas R, Livingston J, Griggs M, Sibai BM. Vitamin C and E supplementation in women at high risk for preeclampsia: a doubleblind, placebo-controlled trial. Am J Obstet Gynecol 2005; 192: 520-521

4 Hubel CA. Oxidative stress in the pathogenesis of preeclampsia. Proc Soc Exp Biol Med 1999; 222: 222-235

5 Sikkema JM, van Rijn BB, Franx A, Bruinse HW, de Roos R, Stroes ES, van Faassen EE. Placental superoxide is increased in pre-eclampsia. Placenta 2001; 22: 304-308

6 Wang $Y$, Walsh SW. Antioxidant activities and mRNA expression of superoxide dismutase, catalase, and glutathione peroxidase in normal and preeclamptic placentas. J Soc Gynecol Investig 1996; 3: 179-184

7 Dekker G, Sibai B. Primary, secondary, and tertiary prevention of preeclampsia. Lancet 2001; 357: 209-215

8 Chappell LC, Seed PT, Briley AL, Kelly FJ, Lee R, Hunt BJ, Parmar K, Bewley $S J$, Shennan AH, Steer PJ, Poston L. Effect of antioxidants on the occurrence of pre-eclampsia in women at increased risk: a randomised trial. Lancet 1999; 354: 810-816

9 Fayyad AM, Harrington KF. Prediction and prevention of preeclampsia and IUGR. Early Hum Dev 2005; 81: 865-876 
10 Asemi Z, Karamali M, Esmaillzadeh A. Effects of calcium-vitamin D cosupplementation on glycaemic control, inflammation and oxidative stress in gestational diabetes: a randomised placebo-controlled trial. Diabetologia 2014; 57: 1798-1806

11 Sharifi N, Amani R, Hajiani E, Cheraghian B. Does vitamin D improve liver enzymes, oxidative stress, and inflammatory biomarkers in adults with non-alcoholic fatty liver disease? A randomized clinical trial. Endocrine 2014; 47: 70-80

12 Asemi Z, Hashemi T, Karamali M, Samimi M, Esmaillzadeh A. Effects of vitamin D supplementation on glucose metabolism, lipid concentrations, inflammation, and oxidative stress in gestational diabetes: a double-blind randomized controlled clinical trial. Am J Clin Nutr 2013; 98: 1425-1432

13 Hypponen E, Cavadino A, Williams D, Fraser A, Vereczkey A, Fraser WD, Banhidy F, Lawlor D, Czeizel AE. Vitamin D and pre-eclampsia: original data, systematic review and meta-analysis. Ann Nutr Metab 2013; 63: $331-340$

14 Haugen M, Brantsaeter AL, Trogstad L, Alexander J, Roth C, Magnus P, Meltzer HM. Vitamin D supplementation and reduced risk of preeclampsia in nulliparous women. Epidemiology 2009; 20: 720-726

15 Wehmeier K, Beers A, Haas MJ, Wong NC, Steinmeyer A, Zugel U, Mooradian $A D$. Inhibition of apolipoprotein AI gene expression by 1,25-dihydroxyvitamin D3. Biochim Biophys Acta 2005; 1737: 16-26

16 Alborzi P, Patel NA, Peterson C, Bills JE, Bekele DM, Bunaye Z, Light $R P$, Agarwal $R$. Paricalcitol reduces albuminuria and inflammation in chronic kidney disease: a randomized double-blind pilot trial. Hypertension 2008; 52: 249-255

17 Rajpathak SN, Xue X, Wassertheil-Smoller S, Van Horn L, Robinson JG, Liu $S$, Allison M, Martin LW, Ho GY, Rohan TE. Effect of $5 \mathrm{y}$ of calcium plus vitamin D supplementation on change in circulating lipids: results from the Women's Health Initiative. Am J Clin Nutr 2010; 91: 894-899

18 Kalra P, Das V, Agarwal A, Kumar M, Ramesh V, Bhatia E, Gupta S, Singh $S$, Saxena $P$, Bhatia $V$. Effect of vitamin D supplementation during pregnancy on neonatal mineral homeostasis and anthropometry of the newborn and infant. Br J Nutr 2012; 108: 1052-1058

19 Poston L, Briley AL, Seed PT, Kelly FJ, Shennan AH. Vitamin C and vitamin $\mathrm{E}$ in pregnant women at risk for pre-eclampsia (VIP trial): randomised placebo-controlled trial. Lancet 2006; 367: 1145-1154

20 Gupta $P$, Narang M, Banerjee BD, Basu S. Oxidative stress in term small for gestational age neonates born to undernourished mothers: a case control study. BMC Pediatr 2004; 4: 14

21 Pisprasert V, Ingram KH, Lopez-Davila MF, Munoz AJ, Garvey WT. Limitations in the use of indices using glucose and insulin levels to predict insulin sensitivity: impact of race and gender and superiority of the indices derived from oral glucose tolerance test in African Americans. Diabetes Care 2013; 36: 845-853

22 Erel 0 . A novel automated direct measurement method for total antioxidant capacity using a new generation, more stable ABTS radical cation. Clin Biochem 2004; 37: 277-285

23 Beutler E, Gelbart T. Plasma glutathione in health and in patients with malignant disease. J Lab Clin Med 1985; 105: 581-584

24 Janero $D R$. Malondialdehyde and thiobarbituric acid-reactivity as diagnostic indices of lipid peroxidation and peroxidative tissue injury. Free Radic Biol Med 1990; 9: 515-540

25 Roth DE. Vitamin D supplementation during pregnancy: safety considerations in the design and interpretation of clinical trials. J Perinatol 2011; 31: 449-459

26 Rosser ML, Katz NT. Preeclampsia: an obstetrician's perspective. Adv Chronic Kidney Dis 2013; 20: 287-296

27 Soheilykhah S, Mojibian M, Moghadam MJ, Shojaoddiny-Ardekani A. The effect of different doses of vitamin $D$ supplementation on insulin resistance during pregnancy. Gynecol Endocrinol 2013; 29: 396-399

28 Ryu OH, Chung W, Lee S, Hong KS, Choi MG, Yoo HJ. The effect of highdose vitamin $\mathrm{D}$ supplementation on insulin resistance and arterial stiffness in patients with type 2 diabetes. Korean J Intern Med 2014; 29: 620-629

29 Strobel F, Reusch J, Penna-Martinez M, Ramos-Lopez E, Klahold E, Klepzig C, Wehrle J, Kahles H, Badenhoop K. Effect of a randomised controlled vitamin $\mathrm{D}$ trial on insulin resistance and glucose metabolism in patients with type 2 diabetes mellitus. Horm Metab Res 2014; 46: 54-58

30 Salehpour A, Shidfar F, Hosseinpanah F, Vafa M, Razaghi M, Amiri F. Does vitamin D3 supplementation improve glucose homeostasis in overweight or obese women? A double-blind, randomized, placebocontrolled clinical trial. Diabet Med 2013; 30: 1477-1481

31 Sengstock DM, Vaitkevicius PV, Supiano MA. Arterial stiffness is related to insulin resistance in nondiabetic hypertensive older adults. J Clin Endocrinol Metab 2005; 90: 2823-2827
32 von Hurst PR, Stonehouse $W$, Coad J. Vitamin D supplementation reduces insulin resistance in South Asian women living in New Zealand who are insulin resistant and vitamin D deficient - a randomised, placebo-controlled trial. Br J Nutr 2010; 103: 549-555

33 Hirschler V, Maccallini G, Tamborenea MI, Gonzalez C, Sanchez M, Molinari C. Improvement in lipid profile after Vitamin D Supplementation in Indigenous Argentine School Children. Cardiovasc Hematol Agents Med Chem 2014; 12: 42-49

34 Schnatz PF, Jiang X, Vila-Wright S, Aragaki AK, Nudy M, O'Sullivan DM, Jackson R, LeBlanc E, Robinson JG, Shikany JM, Womack CR, Martin LW, Neuhouser ML, Vitolins MZ, Song Y, Kritchevsky S, Manson JE. Calcium/vitamin D supplementation, serum 25-hydroxyvitamin D concentrations, and cholesterol profiles in the Women's Health Initiative calcium/vitamin D randomized trial. Menopause 2014; 21: 823-833

35 Alkharfy KM, Al-Daghri NM, Sabico SB, Al-Othman A, Moharram O, Alokail MS, Al-Saleh Y, Kumar S, Chrousos GP. Vitamin D supplementation in patients with diabetes mellitus type 2 on different therapeutic regimens: a one-year prospective study. Cardiovasc Diabetol 2013; 12 : 113, doi:10.1186/1475-2840-12-113

36 Ponda MP, Dowd K, Finkielstein D, Holt PR, Breslow JL. The short-term effects of vitamin D repletion on cholesterol: a randomized, placebocontrolled trial. Arterioscler Thromb Vasc Biol 2012; 32: 2510-2515

37 Auwerx J, Bouillon R, Kesteloot $H$. Relation between 25-hydroxyvitamin D3, apolipoprotein A-I, and high density lipoprotein cholesterol. Arterioscler Thromb 1992; 12: 671-674

38 Chandler PD, Scott JB, Drake BF, Ng K, Manson JE, Rifai N, Chan AT, Bennett GG, Hollis BW, Giovannucci EL, Emmons KM, Fuchs CS. Impact of vitamin D supplementation on inflammatory markers in African Americans: results of a four-arm, randomized, placebo-controlled trial. Cancer Prev Res (Phila) 2014; 7: 218-225

39 Asemi Z, Samimi M, Tabassi Z, Shakeri H, Esmaillzadeh A. Vitamin D supplementation affects serum high-sensitivity C-reactive protein, insulin resistance, and biomarkers of oxidative stress in pregnant women. J Nutr 2013; 143: 1432-1438

40 Wamberg L, Cullberg KB, Rejnmark L, Richelsen B, Pedersen SB. Investigations of the anti-inflammatory effects of vitamin $D$ in adipose tissue: results from an in vitro study and a randomized controlled trial. Horm Metab Res 2013; 45: 456-462

41 Salum E, Kals J, Kampus P, Salum T, Zilmer K, Aunapuu M, Arend A, Eha J, Zilmer M. Vitamin D reduces deposition of advanced glycation endproducts in the aortic wall and systemic oxidative stress in diabetic rats. Diabetes Res Clin Pract 2013; 100: 243-249

42 Fedirko V, Bostick RM, Long Q Flanders WD, McCullough ML, Sidelnikov $E$, Daniel CR, Rutherford RE, Shaukat A. Effects of supplemental vitamin $\mathrm{D}$ and calcium on oxidative DNA damage marker in normal colorectal mucosa: a randomized clinical trial. Cancer Epidemiol Biomarkers Prev 2010; 19: 280-291

43 Ceriello A, Taboga C, Tonutti L, Quagliaro L, Piconi L, Bais B, Da Ros $R$, Motz E. Evidence for an independent and cumulative effect of postprandial hypertriglyceridemia and hyperglycemia on endothelial dysfunction and oxidative stress generation: effects of short- and long-term simvastatin treatment. Circulation 2002; 106: 1211-1218

44 Smith PR, Thornalley PJ. Mechanism of the degradation of non-enzymatically glycated proteins under physiological conditions. Studies with the model fructosamine, $\mathrm{N}$ epsilon-(1-deoxy-D-fructos-1-yl) hippuryl-lysine. Eur J Biochem 1992; 210: 729-739

45 Hamden K, Carreau S, Jamoussi K, Miladi S, Lajmi S, Aloulou D, Ayadi F, Elfeki A. 1Alpha,25 dihydroxyvitamin D3: therapeutic and preventive effects against oxidative stress, hepatic, pancreatic and renal injury in alloxan-induced diabetes in rats. J Nutr Sci Vitaminol (Tokyo) 2009; 55: 215-222

46 Mehta S, Hunter DJ, Mugusi FM, Spiegelman D, Manji KP, Giovannucci EL, Hertzmark E, Msamanga GI, Fawzi WW. Perinatal outcomes, including mother-to-child transmission of HIV, and child mortality and their association with maternal vitamin D status in Tanzania. J Infect Dis 2009; 200: 1022-1030

47 Delvin EE, Salle BL, Glorieux FH, Adeleine P, David LS. Vitamin D supplementation during pregnancy: effect on neonatal calcium homeostasis. J Pediatr 1986; 109: 328-334

48 Mallet E, Gugi B, Brunelle P, Henocq A, Basuyau JP, Lemeur H. Vitamin D supplementation in pregnancy: a controlled trial of two methods. Obstet Gynecol 1986; 68: 300-304

49 Biesalski HK. Vitamin E requirements in parenteral nutrition. Gastroenterology 2009; 137: S92-S104

50 Morley R, Carlin JB, Pasco JA, Wark JD. Maternal 25-hydroxyvitamin $\mathrm{D}$ and parathyroid hormone concentrations and offspring birth size. J Clin Endocrinol Metab 2006; 91: 906-912 


\section{Note of Concern}

Since publication of this article, serious concerns have been raised about the integrity of the reported methods, results and analysis. Responses by the leading author and ethics committees have been unsatisfactory and inconclusive; we advise readers to interpret the information presented in the article with due caution. 